\title{
Apropriações Tecnológicas e Uso de Laboratório de Informática pelos Professores na Escola Municipal Érico Veríssimo, Simões - PI
}

\author{
Nerivaldo Bráz de Carvalho ${ }^{1}$; Lireida Maria Albuquerque Bezerra ${ }^{2}$
}

\begin{abstract}
Resumo: O objeto de análise deste trabalho foi o uso do laboratório de informática pelos os professores da Escola Érico Veríssimo município de Simões - PI e tem como objetivo Identificar o nível de domínio dos professores com o computador e suas principais ferramentas; analisar as prioridades estabelecidas por eles na hora da elaboração e execução das aulas e apoio pedagógico junto ao laboratório de informática descobrir também o que dificultam na vida dos profissionais da educação que não desfrutam gratuitamente desses laboratórios e recursos digitais para fins pedagógicos. Observar como é o funcionamento do laboratório de informática da escola e sua relação com o desenvolvimento do ensino aprendizagem dos alunos. Analisar a contribuição do mesmo para uma aprendizagem significativa, identificando os desafios dos professores e alunos diante do uso desses laboratórios de informática como mecanismo de ensino. Esse trabalho se constitui em uma pesquisa de campo e bibliográfica. O estudo foi fundamentado nas ideias de diferentes autores que versam a respeito do tema, dentre esses estudiosos temos Carvalho (2012), Costa (2015) Pereira (2009) e Sousa (2010). Durante a pesquisa pode-se verificar que é possível incluir no planejamento o uso do laboratório de informática, por ser uma importante ferramenta de ensino. A presente pesquisa tem como propósito principal, investigar se os professores estão utilizando o laboratório de informática implantado na escola para fins pedagógicos. Relatar dados da Escola em ralação à frequência do uso do laboratório de informática; Mostrando os principais direcionamentos com intuito de melhorar o funcionamento da sala de informática.
\end{abstract}

Palavras-Chave: Informática na educação; Ensino; Tecnologia; Laboratório de informática;

\section{Technological Appropriations and Use of Computer Laboratory by Teachers at Érico Veríssimo Municipal School in Simões/PI}

\begin{abstract}
The objective of this work was the use of the computer lab by the teachers of the Érico Veríssimo School in Simões/PI and aims to identify the level of mastery of teachers with the computer and its main tools; To analyze the priorities established by them at the time of the elaboration and execution of the classes and pedagogical support at the computer lab to find out also what they make difficult in the life of the educational professionals who do not enjoy these laboratories and digital resources for pedagogic purposes for free.Observe how the school's computer lab works and its relationship with the development of teaching learning of students. To analyze its contribution to meaningful learning, identifying the challenges faced by teachers and students in the use of these computer labs as a teaching mechanism. This work constitutes a field and bibliographical research. The study was based on the ideas of different authors that talk about the theme, among these scholars we have Carvalho (2012), Costa (2015) Pereira (2009) and Sousa (2010). During the research it can be seen that it is possible to include in planning the use of the computer lab, to be an important teaching tool. The main purpose of this research is to investigate whether teachers are using the computer lab implanted in the school for pedagogical purposes. Report data from the School in relation to the frequency of use of the computer lab; Showing the main directions in order to improve the functioning of the computer room.
\end{abstract}

Keywords: Informatics in education; Teaching; Technology; Computer lab;

\footnotetext{
${ }^{1}$ Graduado em Matemática e Normal Superior - UESPI. Especialista em Psicopedagogia - SOET. Mestrando em Educação pela Anne Sullivan University. E-mail:nerybraz@ hotmail.com;

${ }^{2}$ Graduada em Geografia, Especialista em Ciências na área de Concentração. Mestre em Geografia pela Universidade Federal do Ceará. Email: lireida.mobe@gmail.com
} 
Id on Line Revista Multidisciplinar e de Psicologia

Id on Line Multidisciplinary and Psycology Journal

\section{Introdução}

A sociedade tem vivenciado várias mudanças ocasionadas pela revolução tecnológica, dentre as quais se destacam: o surgimento de uma nova geração tornando cada vez maior a necessidade e busca por conhecimento e informação. Desta forma, as tecnologias de informação e comunicação - TICs surgiram como aliadas nesse processo. Na educação, essas tecnologias chegam como uma nova ferramenta de ensino, abrindo espaço para mudanças nas práticas pedagógicas.

Os laboratórios de informática adquiridos pelas escolas públicas representa um avanço significativo para a melhoria do trabalho dos professores, pois o mesmo trouxe novas possibilidades de avanço no processo ensino aprendizagem, mas para que isso ocorra, é necessário que esses profissionais passem por capacitações para trabalhar com essas ferramentas tecnológicas, de forma a ser incluídas na metodologia de cada disciplina.

As Tecnologias da Informação e Comunicação - TICs crescem em uso e relevância em todo o mundo, sendo muito importante para todos os setores da nossa sociedade. Na educação, as TICS são indispensáveis, haja vista que as atividades pedagógicas que utilizam recursos tecnológicos contribuem de forma significativa e melhoram a qualidade no processo ensino e aprendizagem.

Alguns professores da escola campo de pesquisa, ainda não dominam com eficiência os recursos tecnológicos que a escola dispõe; sentem-se inseguros para usá-las em atividades pedagógicas e como consequência, ignora o uso dos Laboratórios de Informática instalados na escola. Contudo, a falta de formação não é o único fator que explica a pouca utilização dos laboratórios para fins pedagógicos. Existem outros fatores que fazem com que os profissionais da educação não desfrutem gratuitamente desse espaço e recursos digitais na hora da elaboração e execução das aulas.

Esse trabalho se constitui em uma pesquisa com abordagem quanti-qualitativa, com estudo de conceitos baseados em material já elaborado, e como ponto de partida o estudo foi fundamentado nas ideias de diferentes estudiosos da área que idealizam as tecnologias atuais como sendo algo indispensável para a melhoria no ensino da escola campo de pesquisa, dentre outros estudiosos temos esses, Meneses (2014) Almeida (2000) e Valente (1998), dentre outros. 
O presente artigo procura destacar a importância do uso do laboratório de informática na escola municipal Érico Veríssimo, Simões - PI. Fazendo uma avaliação de como está sendo o uso deste laboratório na referida escola. Para isso aborda a seguinte questão: Qual a atual condição do laboratório de informática da escola citada e como está sendo utilizado pelos professores e alunos no processo ensino-aprendizagem?

O objetivo desta pesquisa surgiu a partir do interesse em discorrer sobre a importância da tecnologia na educação e em conhecer como a informática está sendo usada na referida escola tendo em vista que nos dias atuais o professor não consegue fugir do usar dessas ferramentas tecnológicas em suas práticas pedagógicas, pois as mesmas são indispensáveis no mundo de hoje.

São visíveis os avanços e as inovações das tecnologias na atualidade e com elas, vem surgindo a evolução na forma de transmitir conhecimento aos alunos modernos. O presente artigo fala do laboratório de informática existente na escola Érico Veríssimo, se está sendo utilizado pelos professores, se os profissionais de educação estão habilitados para a utilização das ferramentas existente no laboratório e qual a importância do mesmo no processo de ensino aprendizagem.

\section{Utilização do Laboratório de Informática Como Recurso Pedagógico e o Nível de Conhecimento dos Professores no Campo da Tecnologia}

Nos dias de hoje, ainda existem muitos professores que se sentem inseguros na utilização e aplicação de tecnologias da atualidade em sala de aula. Por isso, esses professores concentram-se em aulas tradicionais e pouco atrativas, deixando os alunos muitas vezes desmotivados.

O Ministério da Educação visando promover o uso pedagógico das TICs nas redes públicas de educação básica, bem como a inclusão digital, levou às escolas computadores (laboratórios de informática), recursos digitais e conteúdos educacionais através do Programa Nacional de Informática na Educação - ProInfo. Porém, essa ação não é suficiente para promover a informatização nas escolas. 
Segundo Carvalho (2012), para haver a verdadeira informatização, é necessário o envolvimento de recursos materiais, intelectuais, decisões coletivas e, principalmente, a formação adequada para os profissionais que irão trabalhar com este recurso. Mas, sabe-se que, muitas vezes, a formação do professor para atuar no campo da tecnologia nem sempre acontece.

Segue abaixo a tabulação dos dados obtidos no questionário aplicado aos professores da escola Municipal Érico Veríssimo Simões-PI.

Quanto à formação no campo da tecnologia, 89,3\% dos professores responderam não ter nenhum curso (Figura 1). Portanto, é possível perceber o desinteresse desses professores em buscar novos conhecimentos, principalmente em relação às TICs. Pois já que no município não oferece cursos de formação ou capacitação com frequência, muitos docentes buscam por conta própria outros meios para melhorar sua qualificação nessa área.

Para Costa (2015), o professor deve estar sempre atento às inovações exigidas pela própria profissão, já que o ato de educar requer aprendizagem constantemente. Por isso é de fundamental importância uma formação na área da tecnologia.

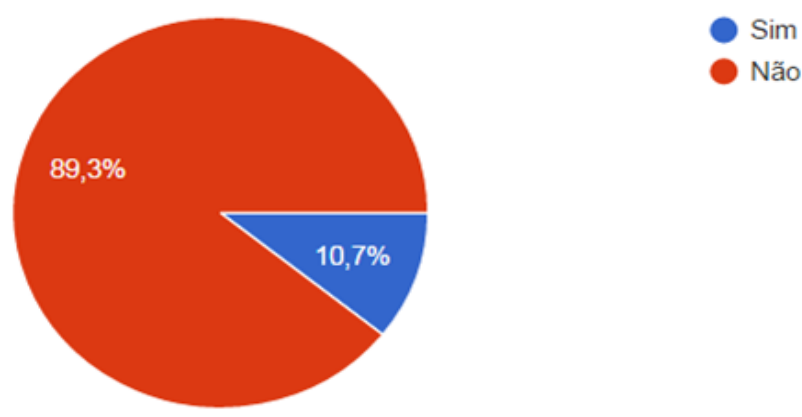

Figura 1 - Formação no campo da tecnologia.

Uma das questões era voltada para o nível de conhecimento sobre informática, sendo que 58,3\% dos professores julgaram ter um nível de conhecimento considerado bom sobre informática, enquanto que $38,1 \%$ afirmaram não ter nenhum conhecimento, ou seja, são totalmente leigos no que se refere às tecnologias e apenas 3,6\% disseram que são ótimos no que se refere às tecnologias (Figura 2). Portanto, se o educador que julga não ter nenhum conhecimento, não buscar uma formação nessa área, continuará com um conhecimento limitado sobre informática. 


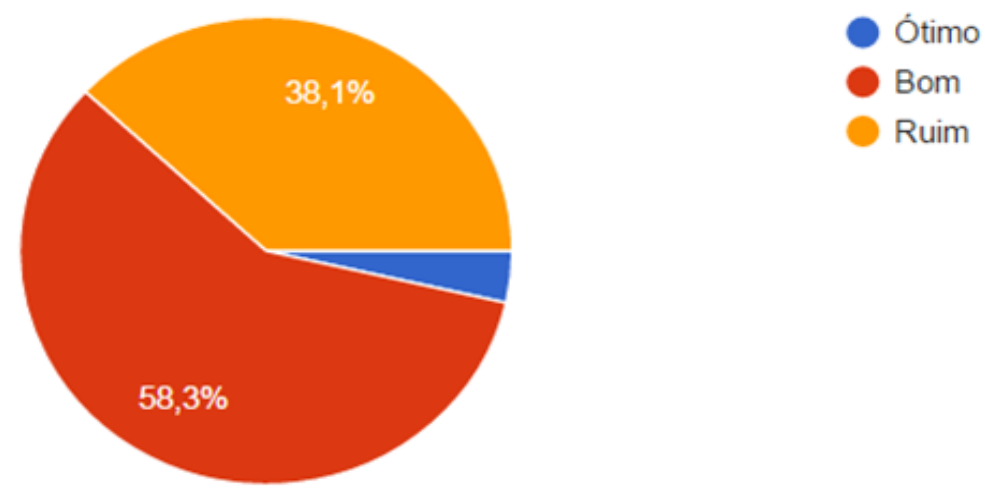

Figura 2 - Nível de conhecimento sobre informática.

Quanto à utilização do laboratório de informática como recurso pedagógico, a realidade é bastante clara, 88,1\% afirmaram não utilizar o ambiente e apenas 11,9\% utiliza o laboratório (Figura 3).

Valente (1998) afirma: o computador não é mais o instrumento que ensina o aprendiz, mas a ferramenta com a qual o aluno desenvolve uma tarefa por intermédio do computador.

Nesta perspectiva o computador é uma ferramenta pedagógica, que devem ser utilizados de modo a auxiliar o professor a compreender que a educação não é somente transferência de conhecimento, mas um processo de construção do mesmo. Por isso a importância da sua utilização por parte dos professores como recurso pedagógico.

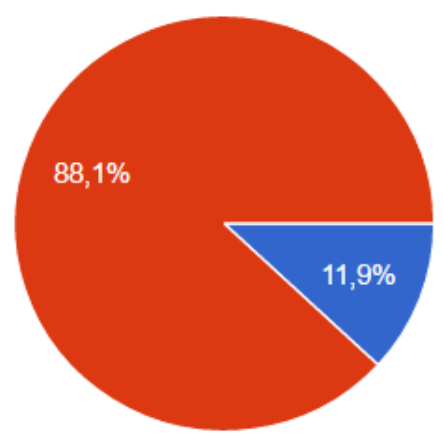

$$
\text { Sim }
$$

Figura 3 - Utilização do Laboratório de Informática como recurso pedagógico.

É possivel perceber que a falta de formação dos professores não é o único fator que dificulta a utilização dos laboratorios de Informática (Figura 4 ). Segundo os professores 
Id on Line Revista Multidisciplinar e de Psicologia

Id on Line Multidisciplinary and Psycology Journal

existem outros fatores, como: conexão de internet ruim, falta de domínio do Sistema Operacional, computadores insuficientes, falta de apoio por parte da direção da escola e a resistência em trabalhar com tecnologia.

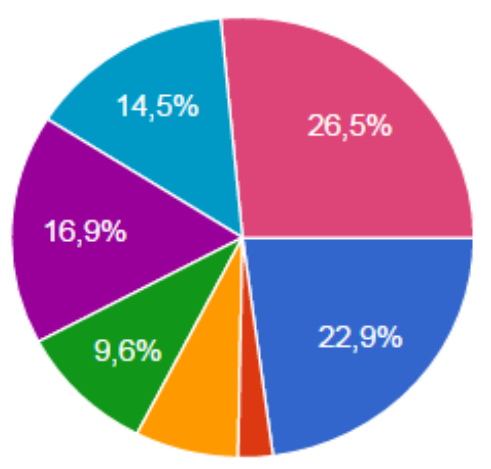

Falta de formação

Resistência em trabalhar com tecnologia

Falta de apoio por parte da direção da escola

Computadores insuficientes

Conexão de internet ruim

falta de domínio do Sistema Operacional

Todas as opções

Figura 4 - Fatores que dificulta a utilização do Laboratório de Informática como auxilío para as praticas pedagogicas.

\section{Fatores que Dificultam os Professores a Utilizar o Laboratório de Informáticas em Sua Prática Pedagógica.}

A partir das observações e do resultado do questionário, foram identificadas duas realidades: a primeira está relacionada com a utilidade que o laboratório tem no cotidiano escolar e a segunda, sobre as dificuldades para explorar mais os recursos de informática.

Os entraves encontrados foram: falta de manutenção nas máquinas, número insuficiente de computadores, falta de profissional da área de informática e a falta de capacitação para os professores. Na sala de informática, existem dez computadores, desses, apenas a metade está funcionando para atender a uma demanda grande de alunos.

Segundo Pereira (2009), inserir recursos tecnológicos na sala de aula requer um bom planejamento para introduzir de forma adequada as TICs, de forma que facilite o processo didático-pedagógico da escola, buscando aprendizagens e a melhoria dos indicadores de desempenho do sistema educacional como um todo, para que as tecnologias sejam empregadas de forma eficiente e eficaz.

$\mathrm{Na}$ escola, os computadores do laboratório quase não são utilizados pelos alunos e professores. Não existe um planejamento didático para explorar tais recursos, às vezes são 
usados por alguns professores quando há necessidade de elaborar atividades para aplicar a seus alunos na sala de aula. Os alunos não têm aulas de informática, o laboratório também não dispõe de softwares educativos que possam ser explorado para dinamizar as aulas e melhorar o desempenho dos educandos.

Conforme mostra o gráfico abaixo sobre a capacitação dos professores, os dados destacam que dos doze docentes pesquisados apenas três disseram possuir conhecimento adequado para trabalhar com recursos tecnológicos, o que equivale a $25 \%$ do corpo docente pesquisado. (Figura 5).

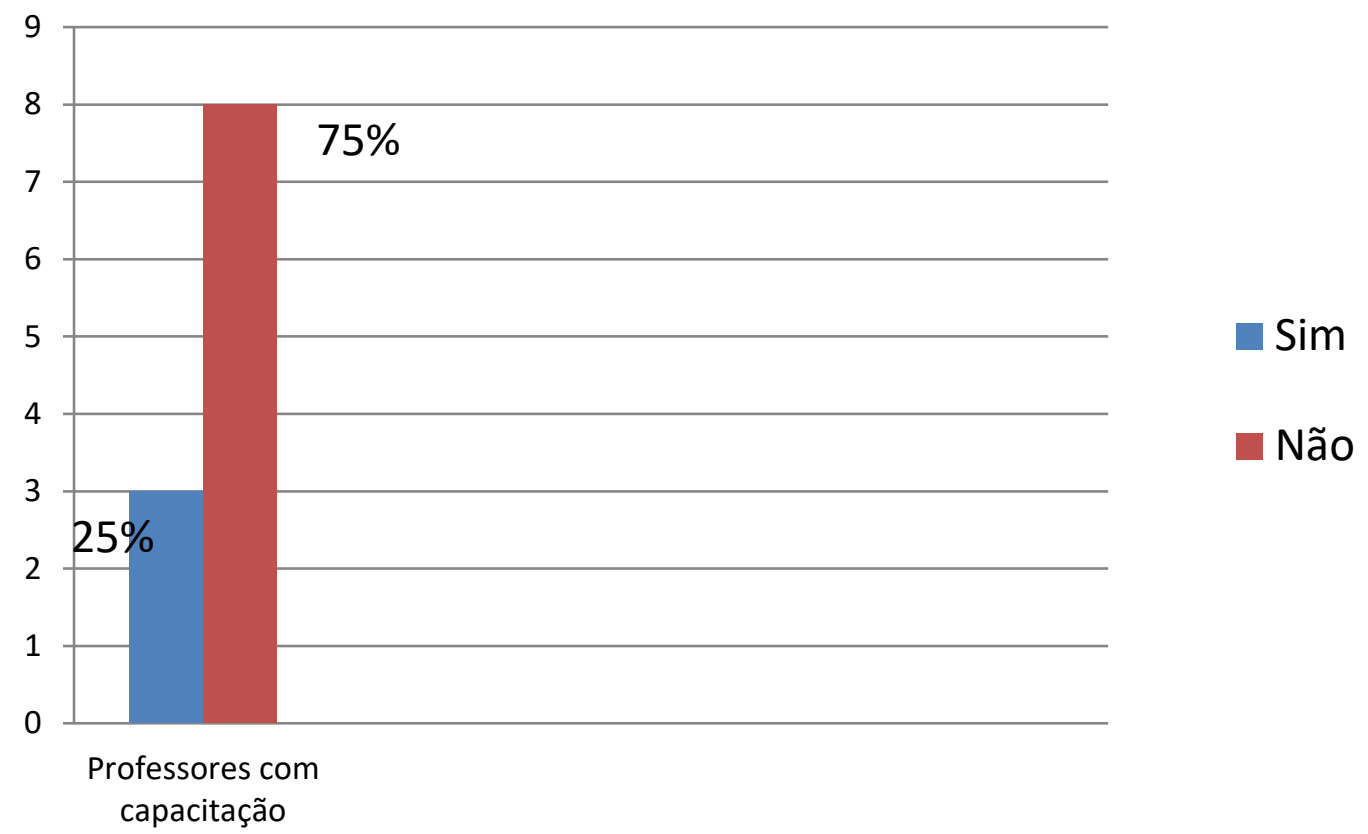

Figura 5 - Pesquisa com os professores sobre capacitação.

Perguntados sobre as dificuldades que os mesmos têm para utilizarem o laboratório, nove dos doze professores pesquisados $(75 \%)$ admitem a resistência em trabalhar com a tecnologia. Os doze educadores $(100 \%)$ alegaram sentir dificuldades para introduzir esses novos recursos no planejamento escolar e na prática pedagógica, oito deles $(66,7 \%)$ disseram que o maior problema é não ter formação adequada e dez $(83,3 \%)$ disseram faltar outros recursos que facilite o manuseio para que eles possam usar de forma inovadora no processo de ensino aprendizagem. (Figura 6). 
Id on Line Revista Multidisciplinar e de Psicologia

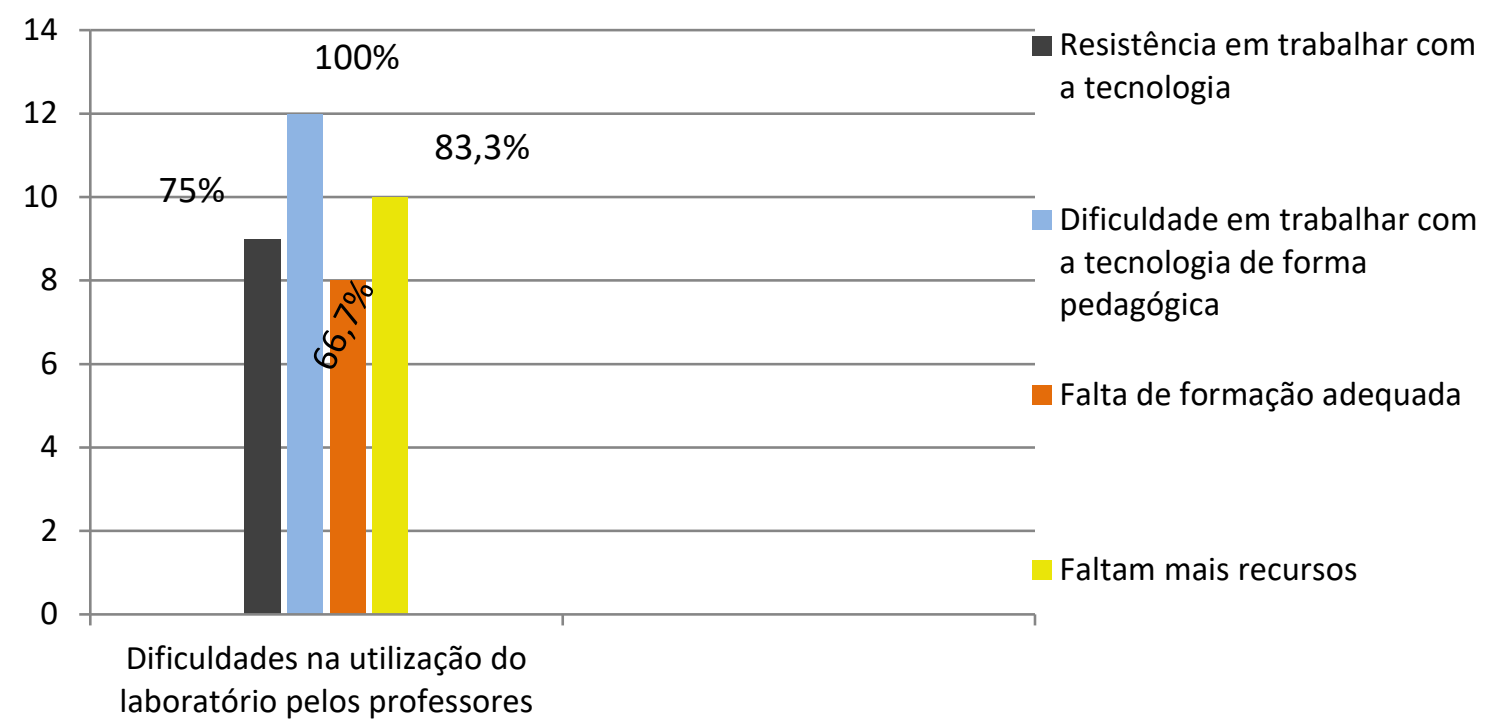

Figura 6 - Pesquisa com os professores sobre as dificuldades na utilização do laboratório.

Para Meneses (2014), a conquista do laboratório de informática é um passo importante, mas sozinha não é o suficiente para se estabelecer uma cultura de uso das TICs nas escolas públicas brasileiras, o desafio maior é fazer com que educadores tenham vontade e motivação para deixarem seus métodos tradicionais e passem a fazer uso de novas linguagens, incluindo a utilização de computadores, trazendo assim as tecnologias para a realidade escolar.

A aquisição das novas tecnologias pelo sistema educacional sofre dificuldades, principalmente porque o corpo docente resiste em fazer uso de computadores e de outras ferramentas digitais em suas práticas docentes mesmo sabendo que os alunos de hoje fazem uso contínuo desses recursos moderno no seu dia a dia.

Desta forma, o trabalho realizado para uma educação digital ainda é insuficiente, pois muitos professores não cumprem o papel de promover a apropriação adequada das tecnologias aos alunos. Mesmo sendo consciente que transmitir os conteúdos das mais diversas disciplinas com o uso dessas ferramentas, tornará as aulas mais dinâmica e prazerosa aproximando assim da realidade vivida por os alunos nesse mundo globalizado.

A escola poderia desenvolver projetos educacionais envolvendo a tecnologia, incluindo dentro das disciplinas aulas nos laboratórios de informática. A utilização de softwares educativos seria uma forma interessante de se trabalhar com os conteúdos vistos em sala de 
Id on Line Revista Multidisciplinar e de Psicologia

Id on Line Multidisciplinary and Psycology Journal

aula, porque contribui com a aprendizagem de forma dinâmica. Porém, além da escola não possuir um plano pedagógico que contemple aulas de informática ou mesmo aulas de outras disciplinas que façam uso da tecnologia, também falta iniciativa de alguns professores e recursos como os softwares educativos.

O uso das tecnologias na educação contribui de forma significativa para o desenvolvimento do ensino aprendizagem, além de atrair a atenção dos alunos, proporciona interatividade, motivação e absorção significativa dos conteúdos. Neste sentido, conforme Nascimento (2007), a informática é um importante recurso pedagógico por meio da qual é possível realizar variadas ações, como se comunicar, fazer pesquisas, redigir textos.

Mesmo com inúmeros benefícios que os avanços das tecnologias atuais proporcionam aos nossos educandos, ainda é muito precária a presença dos alunos no laboratório de informática da escola pesquisada. Por esse motivo torna-se difícil a descrição da frequência do educando no respectivo ambiente.

Neste sentido, Almeida (2000), aponta para a necessidade de desenvolvimento de competências pelo professor para os alunos, tais como: dominar técnicas de programação e recursos dos softwares utilizados de forma a fornecer subsídios aos alunos, além de dominar os conteúdos trabalhados no computador de forma a orientar a aprendizagem.

É comum ouvir dos alunos que não utiliza o laboratório, por não serem estimulados para tal e também por não sentirem necessidade. Alegam serem proibidos a entrar na sala informática, visto que já houve ocorrências de danificações do patrimônio escolar. Todavia, observa-se que o uso do equipamento Data show é um recurso frequentemente utilizado por parte dos professores em várias ocasiões: na exibição de filmes e outros vídeos, slides, etc., a fim de fornecer um suporte a mais durante as aulas, tornando-as mais atrativas, dinâmicas e interativas. Lamentam que esse uso ainda é feito pela minoria dos professores da escola, sendo que a maioria dos educadores preferem aulas tradicionais com metodologias rotineiras.

Alguns equipamentos como notebook, data show, impressora, estão disponíveis para serem utilizados, com autorização e acompanhamento de um professor, para auxiliar os alunos na execução de seminários, apresentações em classe e extraclasse. O uso de tais equipamentos proporciona inúmeros benefícios no desenvolvimento das atividades, promove entretenimento e auxilia na comunicação de forma positiva e eficaz. 
Id on Line Revista Multidisciplinar e de Psicologia

Id on Line Multidisciplinary and Psycology Journal

Com base nisso, Oliveira (2010), aponta que a tecnologia deve ser usada de forma a não dispersar a atenção do aluno, mas buscar sua participação ativa na construção de seu conhecimento, facilitando a interação deste com o conteúdo trabalhado.

É notório que o uso de tecnologias como recurso pedagógico torna as aulas mais interessantes e dinâmicas, além de atrair a atenção dos alunos, contribui para que os conteúdos sejam repassados de forma mais eficiente, atendendo assim os objetivos a ser alcançado que é a aprendizagem dos educandos.

\section{Metodologia}

Os procedimentos metodológicos necessários à realização deste trabalho parte de uma abordagem quanti-qualitativa e foi fundamentada em autores que versam a respeito do tema e através de estudo de campo para o aprofundamento da temática. A mesma mostra a importância da informática como ferramenta na educação e foi desenvolvida com base em observações cotidianas do uso do laboratório da referida escola. E baseada nas respostas obtidas através de um questionário aplicado a doze professores da escola.

O questionário foi utilizado com o objetivo de verificar as principais finalidades do uso do laboratório, se os professores têm capacitação para trabalharem com as TICs e quais as dificuldades encontradas ao trabalhar com esses recursos. A partir da coleta de dados foi possível conhecer a realidade do uso do laboratório da escola e também identificar deficiências existentes. Houve a necessidade de adentrar ao convívio escolar com o intuito de observar, investigar e descobrir se os profissionais de educação da escola estão preparados para utilizar as tecnologias.

A observação aconteceu na escola municipal Érico Veríssimo Simões PI. Os sujeitos pesquisados foram doze professores. A Escola pesquisada funciona em dois turnos, manhã e tarde, do infantil ao fundamental II, composta por 638 alunos e 48 funcionários, sendo 39 professores, 03 auxiliares de sala, 03 coordenadores, 01 diretor, 01 secretaria, 01 auxiliar de secretaria.

Para o desenvolvimento do trabalho foram feitas observações da frequência do uso dos equipamentos do laboratório de informática por parte dos discentes e do desenvolvimento do 
Id on Line Revista Multidisciplinar e de Psicologia

Id on Line Multidisciplinary and Psycology Journal

ensino aprendizagem por meio do uso de tecnologias, observação sistemática do trabalho da gestão e também do trabalho docente na escola em relação ao uso e o funcionamento da sala de informática com o propósito de investigar sobre as apropriações tecnológicas e usos de laboratórios de informática implantados na escola se são usados na prática pedagógica.

É possível comparar os resultados obtidos na observação, a fim de analisar a importância de utilizar as Tecnologias da informação e comunicação na escola Érico Veríssimo, enumerando as dificuldades encontradas pelos professores ao executar as TICS em seus planejamentos pedagógicos.

Considerando-se o uso desta experiência satisfatória, uma vez que as tecnologias atuais é algo de interesse do alunado, e quaisquer mecanismos que as envolvam, numa situação comunicacional, de interação entre estes atores na educação, será tida por eles como interessante e envolvente. O que fará com que seu trabalho como educador, possa fluir diminuído os desafios que envolvem a prática da docência.

\section{Considerações Finais}

Esta pesquisa permitiu conhecer sobre o uso do laboratório de informática da Escola municipal Érico Veríssimo Simões - PI. Mostra um pouco a realidade do ensino das escolas públicas quanto ao uso das tecnologias atuais, principalmente a respeito da utilização do laboratório de informática como espaço de aprendizagem. Foi possível perceber que existe uma precariedade na estrutura dos laboratórios e os poucos recursos tecnológicos existentes no mesmo, não são explorados como deveriam.

A maioria dos professores está acostumado com a metodologia tradicional e por isso faz pouco uso da tecnologia em suas disciplinas, portanto, é necessário que haja uma formação para esses profissionais, de forma que os preparem para lidar com as TICs. Em relação à escola, é importante a adoção de um planejamento pedagógico que inclua os recursos tecnológicos como ferramentas obrigatórias no processo de ensino-aprendizagem.

Verificou-se que a escola campo de pesquisa ainda precisa melhorar o funcionamento e o uso do laboratório de informática. O referido local ainda é pouco frequentado pelos alunos e professores. Alguns profissionais de educação alegam que a quantidade de equipamentos é insuficiente para atender a demanda, outros dizem que não estão preparados para trabalhar com 
Id on Line Revista Multidisciplinar e de Psicologia

Id on Line Multidisciplinary and Psycology Journal

tais ferramentas e se sentem inibidos por acharem que os alunos dos dias de hoje tem mais habilidades com as tecnologias do que eles, por isso não introduz no seu planejamento.

Entende-se que a ação destes últimos, está prejudicando o desenvolvimento do bom uso do laboratório, fato que justifica a pouca frequência dos alunos a sala de informática. Pode-se perceber que os alunos tem bastante interesse em assistir aulas com uso das tecnologias atuais. Relatam que consegue assimilar os conteúdos de forma prazerosa e menos monótona. Constatou-se ainda que, existe uma grande preocupação por parte da gestão em preservar os equipamentos do local.

O professor adquire papel relevante nas transformações dos métodos de ensino, cabendo a esses profissionais despertar o interesse dos alunos, mediando à construção do conhecimento, por meio do uso desses novos recursos. Portanto, as tecnologias atuais representam um novo paradigma educacional e os professores por sua vez, devem aperfeiçoar seus conhecimentos diante das tecnologias modernas à medida que a sociedade se modifica.

Diante da reflexão realizada nesta pesquisa, conclui-se que um profissional de educação atuante deve interagir cada vez mais com o meio, com a contemporaneidade e para tanto, novas experiências serão imprescindíveis e decisivas tornando suas aulas mais atrativas.

Através desta pesquisa pode-se perceber que a maioria dos professores da Escola campo de pesquisa não tem formação na área de tecnologia. Desse modo, esses professores resistem em trabalhar com as tecnologias disponibilizadas na escola, bem como o uso do laboratório de informática para fins pedagógicos. Porém, a falta de formação não é o único fator que explica a resistência dos mesmos. Alguns professores não veem a inserção das tecnologias como auxílio em sua prática pedagógica e sim como um trabalho a mais.

No decorrer da pesquisa constatou-se que as atividades pedagógicas que utilizam recursos tecnológicos auxiliam o profissional no ato de educar. Portanto, é essencial que os professores reflitam sobre a importância das TICs para a educação e que possam a partir dessa reflexão, explorá-las mais em sala de aula. Porém, para que isso aconteça, o profissional de educação deve vencer todos esses obstáculos para poder proporcionar ao aluno maior motivação e interesse, trazendo assim melhoria no processo de ensino e aprendizagem.

Conclui-se que são poucos os docentes que estão bem familiarizados com o uso e manuseio dos equipamentos. Esses professores utilizam com frequências em suas aulas algumas ferramentas tecnológicas existentes na escola e entendem que as mesmas são bons 
Id on Line Revista Multidisciplinar e de Psicoloqia

Id on Line Multidisciplinary and Psycology Journal

recursos que servirão de suporte e que fornece inúmeras possibilidades pedagógicas que pode melhorar o processo de aprendizagem dos alunos.

\section{Referências}

ALMEIDA, Maria Elizabete de. Proinfo: Informática e formação de professores. Secretaria de Educação à Distância. Brasília: Ministério da Educação, Seed, 2000.

CARVALHO, J. M. de. O uso pedagógico dos laboratórios de informática nas escolas de Ensino Médio de Londrina. Universidade Estadual de Londrina, 2012.

COSTA, V. da S. L. Os desafios dos profissionais de biologia na inclusão de alunos com deficiência. Monografia (Licenciatura Plena em Ciências Biológicas) - Universidade Federal do Piauí. Centro de Educação à Distância, Simões - PI, 2015.

MENEZES, Antonia Deiziane Alves. A importância dos laboratórios de informática em uma escola classe: diagnósticos e desafios. Brasília: Universidade de Brasília, 2014.p.17.

NASCIMENTO, João Kerginaldo Firmino do. Informática aplicada à educação. Brasília: Universidade de Brasília, 2007;

OLIVEIRA, Déborah Ruchiga de; PACHECO, Samuel Bueno. Informática na Educação 2, v.3 - Rio de Janeiro: Fundação CECIERJ, 2010.

PEREIRA, Bernadete Terezinha. O uso das tecnologias da informação e comunicação na prática pedagógica da escola. Paraná: UFPR, 2009.

VALENTE, J. A.; ALMEIDA, F. J. de. Visão Analítica da Informática na Educação no Brasil: a questão da formação do professor. Revista Brasileira de Informática na Educação, v. 1, n. 1, p. 1-28, 1998. Disponível em: < http://www.lbd.dcc.ufmg.br/colecoes/rbie/1/1/004.pdf>.Acesso

Como citar este artigo (Formato ABNT):

CARVALHO, N.B.; BEZERRA, L.M.A. Apropriações tecnológicas e uso de laboratório de informática pelos professores na Escola Municipal Érico Veríssimo, Simões - PI. Id on Line Revista Multidisciplinar e de Psicologia, Janeiro de 2017, vol.10, n.33, Supl 2. P. 173-185. ISSN: 1981-1179. 